\title{
Transient Stability Analysis of Power System by Coordi- nated PSS-AVR Design Based on PSO Technique
}

\author{
Ali Darvish Falehi, Mehrdad Rostami, Hassan Mehrjardi \\ Department of Engineering, Shahed University, Tehran, Iran \\ E-mail: \{darvishfalehi,rostami\}@shahed.ac.ir \\ Received March 8, 2011; revised April 1, 2011; accepted April 19, 2011
}

\begin{abstract}
In this paper, Power System Stabilizer (PSS) and Automatic Voltage Regulator (AVR) are coordinated to improve the transient stability of generator in power system. Coordinated design problem of AVR and PSS is formulated as an optimization problem. Particle Swarm Optimization (PSO) technique is an advanced robust search method by the swarming or cooperative behavior of biological populations mechanism. The performance of PSO has been certified in solution of highly non-linear objectives. Thus, PSO technique has been employed to optimize the parameters of PSS and AVR in order to reduce the power system oscillations during the load changing conditions in single-machine, infinite-bus power system. The results of nonlinear simulation suggest that, by coordinated design of AVR and PSS based on PSO technique power system oscillations are exceptionally damped. Correspondingly, it's shown that power system stability is superiorly enhanced than the uncoordinated designed of the PSS and the AVR controllers.
\end{abstract}

Keywords: Power System Satiability, Coordinated Design, PSS, AVR, Particle Swarm Optimization

\section{Introduction}

In recent years, large signal stability problems have been reported in power systems and which originated broad studies in many literatures [1-5]. Power system is affected by high electromechanical oscillations while a disturbance occurs, which may lead to loss of synchronism of generators. Thus, high performance excitation systems are essential to maintain steady state and transient stability of generators and provide rapid control and recover of terminal voltage [6,7]. The generator excitation system using an automatic voltage regulator (AVR) maintains the terminal voltage magnitude of a synchronous generator to a defined level [8]. It also plays an essential role to control the reactive power and improve the stability. AVR assists improving the steady-state stability of power systems [9]. In transient state, machine is affected by severe impacts, mostly in a short time which causes severe drop on the terminal voltage of machine.

Generally, a controller to increase damping of electromechanical oscillations is known as power system stabilizer (PSS), which is basically kind of classical phase compensator $[10,11]$. They are used to compensate the negative damping of AVR [12]. Also, PSS modulates the input signal of excitation system to damp out rotor oscillations.

A variety of conventional design techniques can be used to tune controller parameters. The most common methods are based on the pole placement method [13,14], eigenvalues sensitivities $[15,16]$, residue compensation [17], and also the current control theory.

Lucklessly, the conventional methods are time consuming as they are repetitive and need heavy computation burden beside of slow convergence. In addition, process is sensitive to be trapped in local minima and the obtained response may not be optimal [18].

The progressive methods develop a technique to search for the optimum solutions via some sort of directed random search processes [19]. A suitable trait of the evolutionary methods is to search for solutions without prior problem perception.

In recent years, a number of various ingenious computation techniques namely: Simulated Annealing (SA) algorithm, Evolutionary Programming (EP), Genetic Algorithm (GA), Differential Evolution (DE) and Particle Swarm Optimization (PSO) have been employed by scholars to solve the different optimization problems of electrical engineering [8,18-29]. But, the PSO technique can produce an excellent solution within shorter calculation time and stable convergence characteristic than other 
stochastic techniques [8]. In fact, PSO is a stochastic global optimization approach based on swarm behavior such as fish and bird schooling in nature [30]. Generally, PSO is known as a simple concept, easy to perform, and computationally effective. PSO has a flexible and well-balanced mechanism to enhance the global and local exploration abilities [31].

Thus, PSO technique has been selected to coordinate the operation of both the PSS and AVR controllers in order to improve the transient stability and diminish the power system oscillations.

To appraise the coordinated design problem of these devices, a severe disturbance condition is considered in the transmission line of single-machine, infinite-bus power system. Furthermore, effect of coordinated design of these devices is assessed in spite of changes in the loading of the generator.

\section{Power System Structure and Modeling}

The model of electrical power system is exhibited in Figure 1, which is comprised of a generating unit connected to electrical network through a transformator. It is almost similar to the power system used in [23]. The generator is equipped with hydraulic turbine and governor (HTG). Also, excitation system furnished with an automatic voltage regulator (AVR) and a power system stabilizer (PSS) to maintain the terminal voltage and to damp oscillations. Speed deviation of generator is chosen as the input signal of the PSS. The single-machine, infinite-bus power system has been simulated using MATLAB/SIMULINK environment. All of the other relevant parameters are given in Appendix.

\subsection{Automatic Voltage Regulator Model}

A first order AVR model is used in this paper which is almost derived from ref $[5,32]$. The block diagram of the model is shown in Figure 2.

The parameters to be adjusted, on the model of AVR presented in Figure 2, are: the gain $K_{a}$ and the time constant $T_{a}$. The values of the parameters: $\mathrm{K}_{\mathrm{f}}, T_{f}$ and $T_{r}$ are considered $0.001,0.1$ and 0.02 respectively [33].

\subsection{Power System Stabilizer Model}

PSS includes a transfer function comprise of an amplification block, a wash out block and lead-lag block and sensor time constant $[12,19]$. The PSS input signal can be either the speed deviation or active power. The structure of the PSS controller is presented in Figure 3. The value of $T_{W S}$ and sensor delay time are considered 3 and $15 \mathrm{~ms}$ respectively. Parameters of the power system stabilizer, including: gain $\left(\mathrm{K}_{\mathrm{P}}\right)$ and the time constants $\left(T_{1 P}\right.$ and $T_{2 P}$ ) shall be determined.

\subsection{Coordinated Design of AVR and PSS}

In this study, the PSS and AVR controller are designed and optimized by minimizing objective function in order to enhance the system response in terms of the settling time, overshoots and undershoot. There are many different methods to appraise the response performance of a control system, for example: integral of time weighted absolute value of error (ITAE), integrated absolute error(IAE), integral of squared error (ISE), and integral of time weighted squared error (ITSE) [34]. In this paper, the integral time absolute error (ITAE) of the speed signal deviation is considered as the fitness function J [18]. This fitness function is determined as:

$$
J=\int_{t=0}^{t=t_{\text {sin }}}|\Delta \omega| \cdot t . d t
$$

where, $\Delta \omega$ is the speed deviation in and $\boldsymbol{t}_{\sin }$ is the time range of the simulation. The time-domain simulation of the nonlinear system model was performed for the simulation period. It is aimed to minimize this fitness function in order to improve the system response in terms of the settling time and overshoots. The problem constraints are the PSS and AVR parameter bounds. Therefore, the design

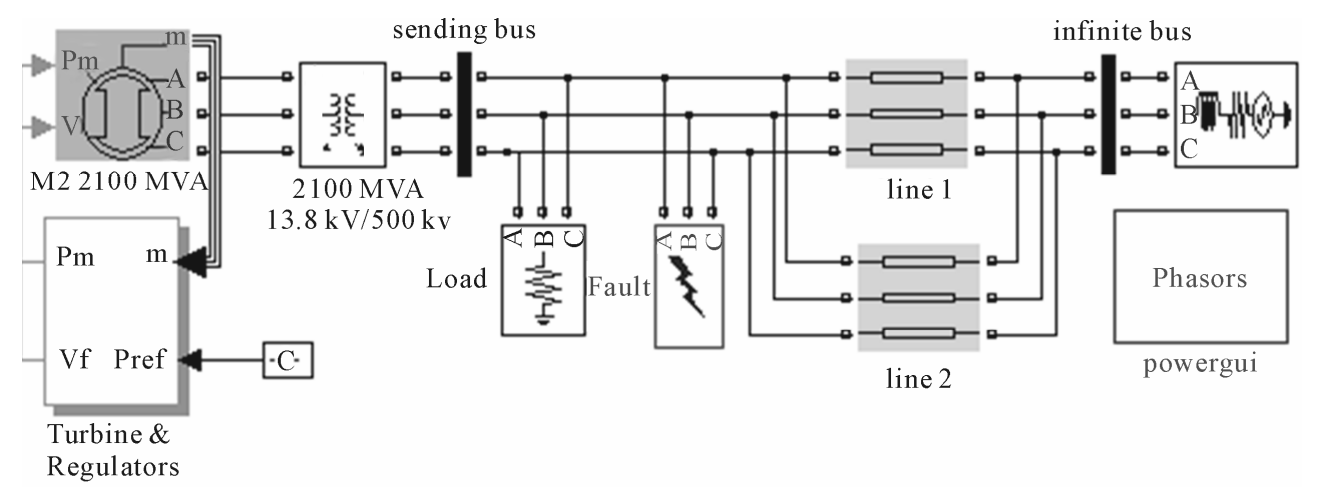

Figure 1. Single-machine, infinite-bus power system. 


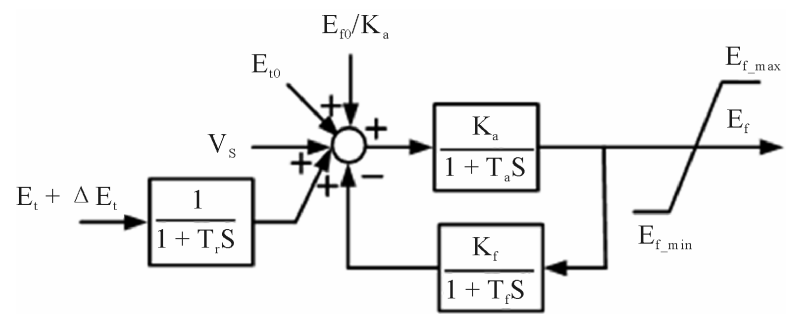

Figure 2. AVR first order model with feedback.

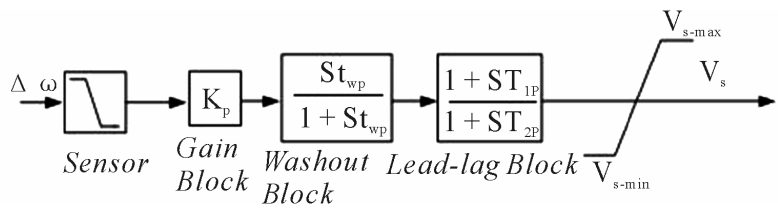

Figure 3. Structure of the power system stabilizer.

problem can be formulated as the following optimization problem:

\section{Minimize $J$}

Subject to:

$$
\begin{array}{ll}
K_{P}^{\min } & \leq K_{P} \leq K_{P}^{\max } \quad K_{a}^{\min } \leq K_{a} \leq K_{a}^{\max } \\
K_{1 P}^{\min } & \leq K_{1 P} \leq K_{1 P}^{\max } \quad K_{a}^{\min } \leq K_{a} \leq K_{a}^{\max } \\
K_{2 P}^{\min } & \leq K_{2 P} \leq K_{2 P}^{\max }
\end{array}
$$

PSO technique is applied to solve the coordinated design problem and optimal set of PSS and AVR parameters.

\section{Description of the Implemented Particle Swarm Optimization Technique}

PSO is a stochastic global optimization method, which has been motivated by the behavior of organisms, such as fish schooling and bird flocking. Simplicity and fast convergence rate is the important characteristic of this technique [35]. PSO has the flexibility than other heuristic algorithms to control the balance between the global and local configuration of the search space. This unique feature of PSO vanquishes the premature convergence problem and enhances the search capability. Also unlike the traditional methods, the solution quality of this technique does not depend on the initial population. Starting anywhere in the search space, PSO algorithm ensures the convergence of the optimal solution. The following is a brief introduction to PSO [36]. In the current research, the process of PSO technique can be summarized as follows [37]:

- Initial positions of pbest (personal best of agent $i$ ) and gbest are (group best) varied. However, using the different direction of pbest and gbest, all agents piecemeal receive near-by the global optimum.

- Adjustment of the agent position is perceived by the position and velocity information. However, the method can be used to the separate problem applying grids for XY position and its velocity.

- Didn't have any incompatibilities in searching procedures even if continuous and discrete state variables are utilized with continuous axes and grids for $\mathrm{XY}$ positions and velocities. Namely, the method can be applied to mixed integer non-linear optimization problems with continuous and district state variables easily and naturally.

- The above statement is based on using only XY axis (two dimensional spaces). Thus, this method can be easily employed for $\mathrm{n}$-dimensional problem.

The modified velocity and position of each particle can be calculated using the current velocity and the distances from the pbest $t_{j, g}$ to gbestg as presented in the following equations [38]:

$$
\begin{gathered}
v_{j, g}^{(t+1)}=w \times v_{j, g}^{(t)}+c_{1}+r_{1} \times\left(\text { pbest }_{j, g}-x_{j, g}^{(t)}\right) \\
+c_{2}+r_{2} \times\left(\text { gbest }_{g}-x_{j, g}^{(t)}\right) \\
x_{j, g}^{(t+1)}=x_{j, g}^{t}+v_{j, g}^{(t+1)} \\
\text { with } j=1,2, \cdots n \text { and } g=1,2, \cdots . m
\end{gathered}
$$

where $n$ is the number of particles in the swarm; $m$ is the number of components for the vectors $v_{j}$ and $x_{j}, t$ is the number of generation (iteration); $v_{j, g}^{(t)}$ is the gth component of the velocity of particle $j$ at iteration $t$

$$
v_{g}^{\min } \leq v_{j, g}^{(t)} \leq v_{g}^{\max }
$$

where $c_{1}$ and $c_{2}$ are two positive constants, called cognitive and social parameters respectively. $r_{1}$ and $r_{2}$, are random numbers, uniformly distributed in $(0,1) . x_{j, g}^{(t)}$ is the gth component of the position of particle $j$ at iteration $t$; pbest $t_{j}$ is the pbest of particle $j$; pbest is the pbest of the group.

$w$ is the inertia weight, which produces a balance between global and local explorations requiring less iteration on average to find a suitably optimal solution. It is determined by the following equation:

$$
w=w_{\max }-\frac{w_{\max }-w_{\min }}{i \text { ter } r_{\max }} \times \text { iter }
$$

where $w_{\max }$ is the initial weight, $w_{\min }$ is the final weight, iter is the current iteration number, ite $_{\max }$ is the maximum iteration number.

The jth particle in the swarm is represented by a d-dimensional vector $X_{j}=\left[X_{j, 1}, X_{j, 2}, \cdots, X_{j, d}\right]$ and its rate of velocity is symbolized by another d-dimensional vector $v_{j}=\left[v_{j, 1}, v_{j, 2}, \cdots, v_{j, d}\right]$. The best previous posi- 
tion of the $j$ th particle is represented by pbest $_{j}=\left[\right.$ pbest $_{j, 1}$, pbest $_{\mathrm{j}, 2}, \cdots$, pbest $\left._{j, d}\right]$. The index of best particle among all of the particles in the population is represented by the gbest. In PSO, each particle moves in the search space for seeking the best global minimum (or maximum). The velocity update in a PSO comprises of three parts; namely cognitive, momentum and social parts. The performance of PSO algorithm depends upon the balance among these parts. The parameters $c_{1}$ and $c_{2}$ determine the relative pull of pbest and gbest and the parameters $r_{1}$ and $r_{2}$ help in stochastically varying these pulls.

Ultimately the flowchart of proposed optimization algorithm is shown in Figure 4.

\section{Simulation Results}

To assess the coordinated control AVR and PSS, three different operating positions with different Fault Clearing Time (FCT) are considered, which are exhibited in Table 1.

\subsection{Nominal Loading}

A 3-phase fault located at sending bus and triggered at $\mathrm{t}=$ $1 \mathrm{sec}$, then be cleared after $0.262 \mathrm{sec}(\mathrm{FCT}=1.262 \mathrm{sec})$. PSO technique is employed to coordinate among AVR and PSS controllers, and also to optimal tune the parameters of these devices. Optimal parameters of AVR and PSS are presented in Table 2.

The system responses under this severe disturbance are presented in Figures 5-7. These figures approve the coordination between AVR and PSS controllers in order to improve the power system stability. Also, power system oscillations have been improved significantly as compared to non-coordination of these devices.

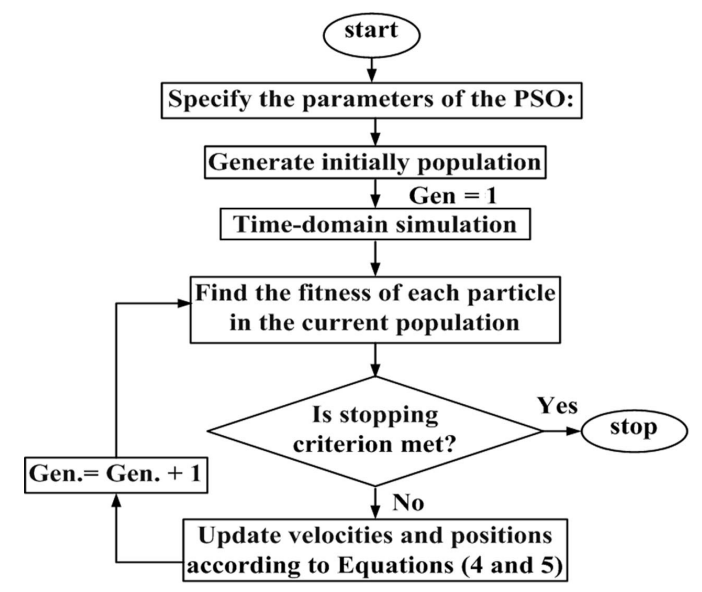

Figure 4. Flowchart of the PSO technique.
Table 1. Loading positions considered.

\begin{tabular}{cccc}
\hline Loading conditions & $P_{e}(\mathrm{pu})$ & $\delta_{0}(\mathrm{deg})$ & $\mathrm{FCT}(\mathrm{sec})$ \\
\hline Small & 0.35 & 19.6 & 0.454 \\
Nominal & 0.7 & 42.2 & 0.262 \\
Heavy & 0.95 & 58 & 0.133 \\
\hline
\end{tabular}

Table 2. Optimal parameter settings of the AVR and PSS.

\begin{tabular}{ccccc}
\hline \multicolumn{3}{c}{ AVR } & \multicolumn{3}{c}{ PSS } \\
\hline$K_{a}$ & $T_{a}$ & $K_{P}$ & $T_{1 P}$ & $T_{2 P}$ \\
292.8481 & 0.0031 & 4.9759 & 0.1493 & 1.1971 \\
\hline
\end{tabular}

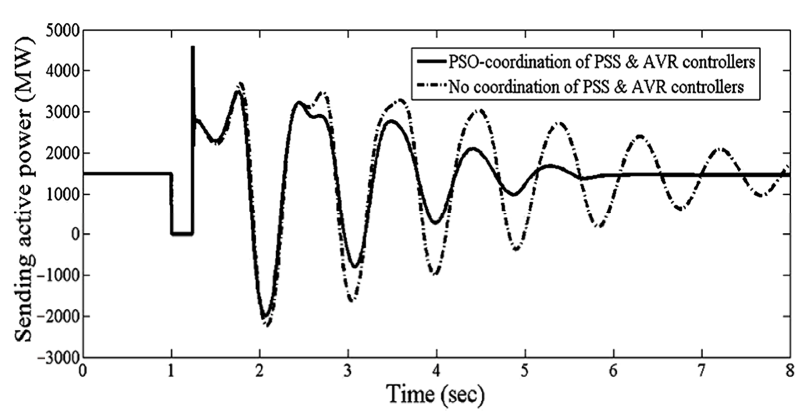

Figure 5. Active power generation response for 3-ph fault in transmission line with nominal loading.

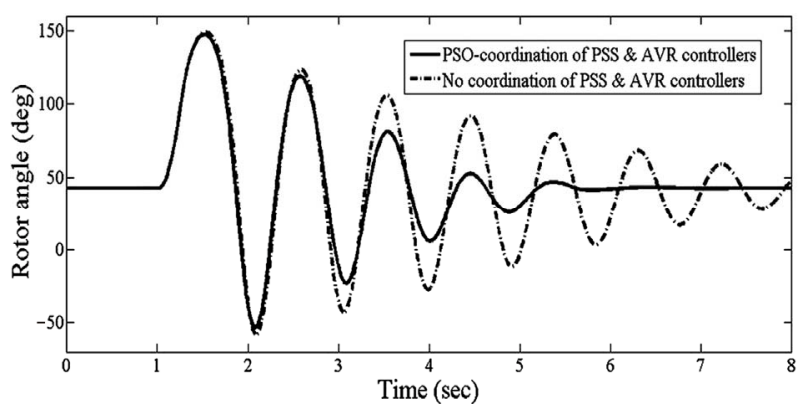

Figure 6. Power angle response for 3-ph fault in transmission line with nominal loading.

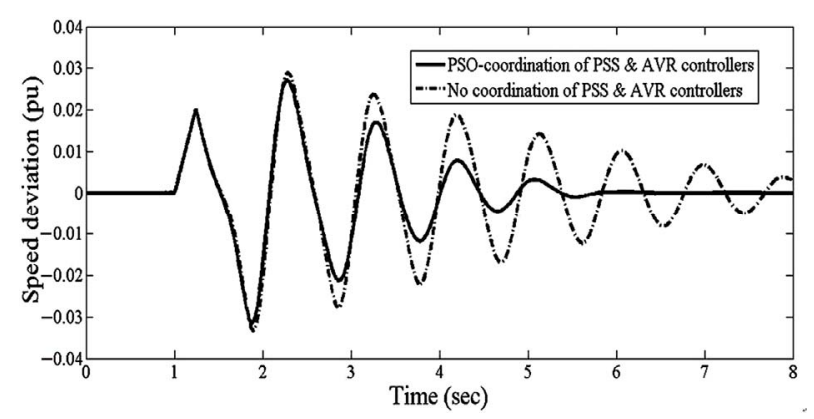

Figure 7. Speed deviation response for 3-ph fault in transmission line with nominal loading. 


\subsection{Heavy Loading}

In this state, to appraise the coordinated design problem, it is considered that the generator loading experiencing heavy step change as shown in Table 1. The 3-phase fault occurs at $t=1 \mathrm{sec}$, then it is cleared after $0.133 \mathrm{sec}$. System responses under such 3-phase fault are displayed in Figures 8-10. Obviously by optimal coordination of AVR and PSS, power system stability is superiorly enhanced.

\subsection{Small Loading}

The robustness of coordination among the AVR and PSS is also verified when generator loading is altered to small

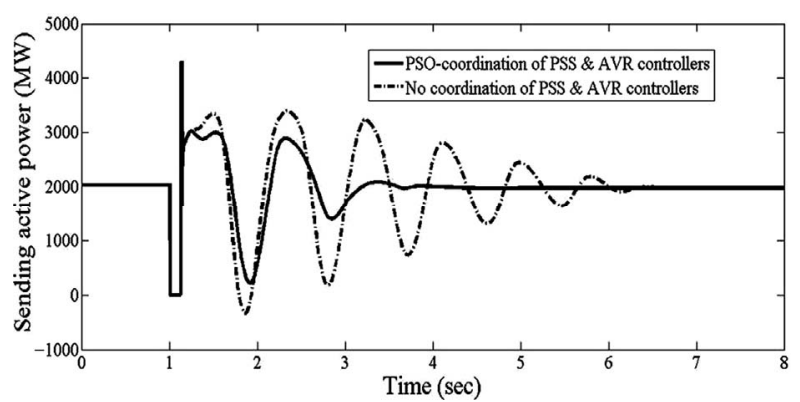

Figure 8. Active power generation response for 3-ph fault in transmission line with heavy loading.

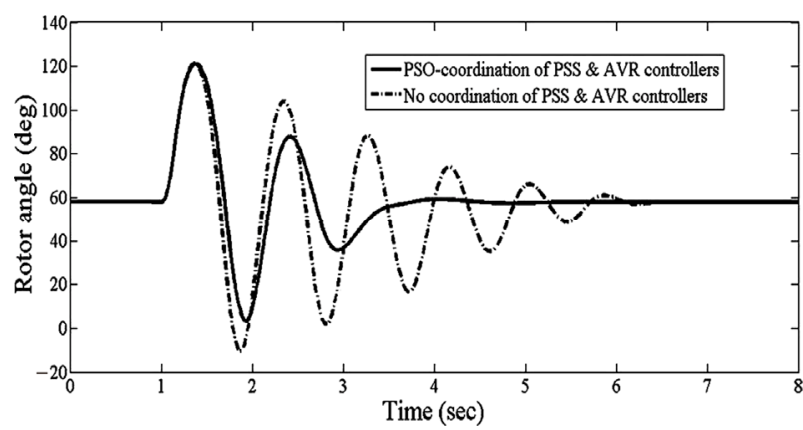

Figure 9. Power angle response for 3-ph fault in transmission line with heavy loading.

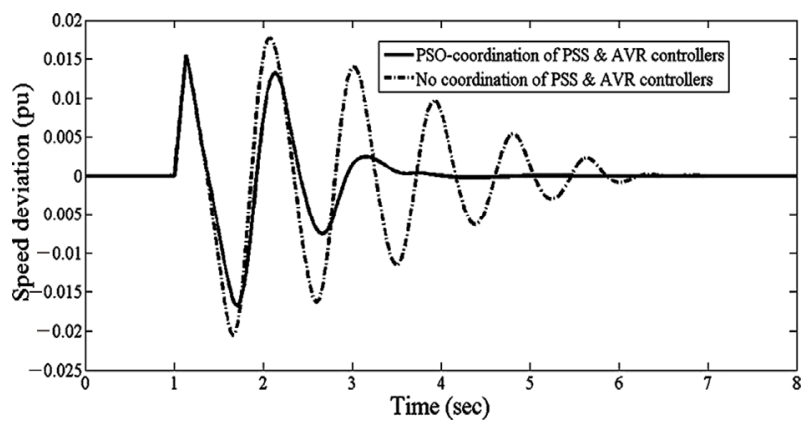

Figure 10. Speed deviation response for 3-ph fault in transmission line with heavy loading. loading. 3-phase fault happened at $t=1 \mathrm{sec}$, subsequently fault is cleared after 0.454 secat $t=1.454 \mathrm{sec}$. System responses under such 3-phase fault are displayed in Figures 11-13. As it has been expected like to two before cases, the power system stability is significantly improved by coordinated control between AVR and PSS rather than despite the non-coordination of these devices.

\section{Conclusions}

This paper presents the particle swarm optimization algorithm for the simultaneous coordinated design of the AVR and PSS in order to enhance the power system stability. Time domain simulations are performed to demonstrate the efficiency of proposed optimization method.

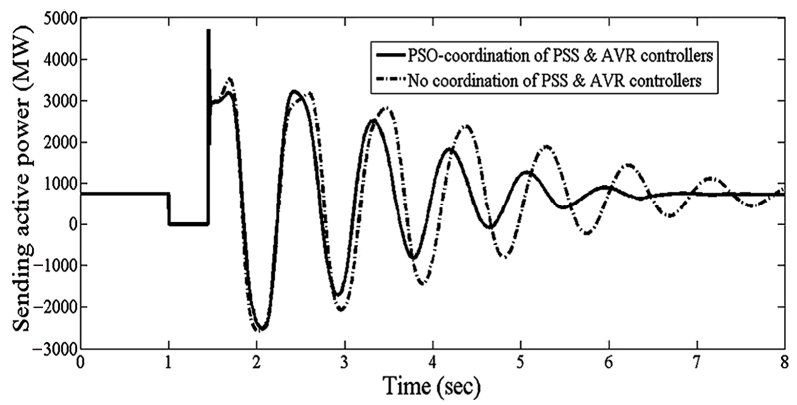

Figure 11. Active power generation response for 3-ph fault in transmission line with small loading.

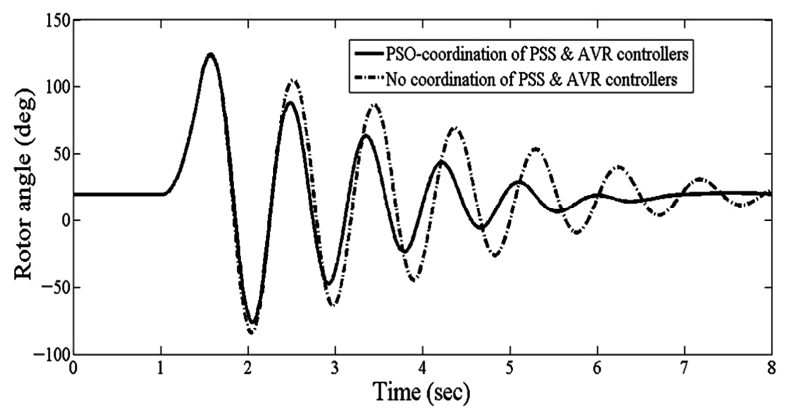

Figure 12. Power angle response for 3-ph fault in transmission line with small loading.

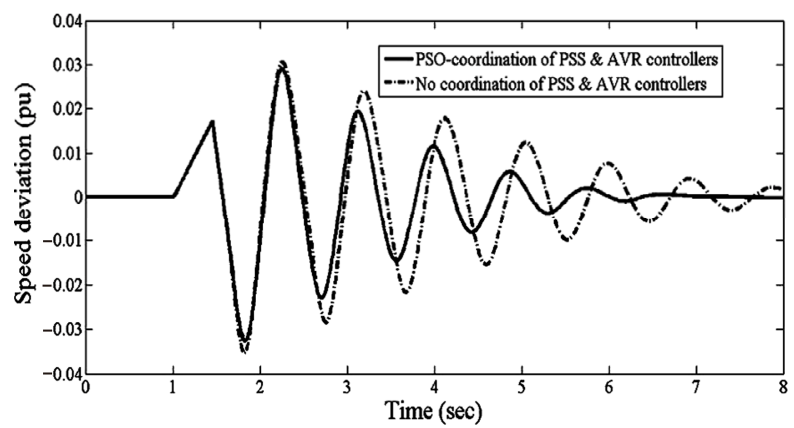

Figure 13. Speed deviation response for 3-ph fault in transmission line with small loading. 
Coordination among these devices based on PSO technique has been deeply investigated under severe disturbance for single-machine, infinite-bus power system. To confirm the robustness of coordinated design of these controllers, power system stability has been assessed in spite of load changes of generator. Also, the particular features of PSO algorithm namely its superior computation efficiency and high accuracy solutions have been approved. Finally, the results of non-linear simulation have shown that by using PSO technique, power system transient stability dramatically improves as compared to non-optimized parameters of PSS and AVR.

\section{References}

[1] M. B. Duric, Z. M. Radojevic and E. D. Turkovic, "A Reduced Order Multi Machine Power System Model Suitable for Small Signal Stability Analysis," Electrical Power and Energy Systems, Vol. 20, No. 5, 1998, pp. 369-374.

[2] H. Yassami, A. Darabi and S. M. R. Rafiei, "Power System Stabilizer Design Using Strength Pareto Multi-Objective Optimization Approach," Electric Power Systems Research, Vol. 80. No. 7, 2010, pp. 838-846. doi:10.1016/j.epsr.2009.12.011

[3] V. Mukherjee and S. P. Ghoshal, "Comparison of Intelligent Fuzzy Based AGC Coordinated PID Controlled and PSS Controlled AVR System," Electrical Power and Energy Systems, Vol. 29, No. 9, 2007, pp. 679-689. doi:10.1016/j.ijepes.2007.05.002

[4] S. Gomes Jr., N. Martins and C. Portela, "Computing Small-Signal Stability Boundaries for Large-Scale Power Systems," IEEE Transactions on Power Systems, Vol. 18, No. 2, 2003, pp. 747-752. doi:10.1109/TPWRS.2003.811205

[5] C. Liu, R. Yokoyama, K. Koyanagi and K. Y. Lee, "PSS Design for Damping of Inter-Area Power Oscillations by Coherency-Based Equivalent Model," Electrical Power and Energy Systems, Vol. 26, No.7, 2004, pp. 535-544. doi:10.1016/j.ijepes.2004.01.007

[6] F. P. Demello and C. Concordla, "Concepts of synchronous Machine Stability as Affected by Excitation Control," IEEE Transactions, Power Apparatus System, Vol. 88, No. 4, pp. 189-202, 1969. doi:10.1109/TPAS.1969.292452

[7] M. Klein, G. J. Rogers and P. Kundur, "A Fundamental Study of Inter-Area Oscillations in Power Systems," IEEE Transaction on Power Systems, Vol. 6, No. 3, 1991, pp. 914-921. doi:10.1109/59.119229

[8] A. M. El-Zonkoly, A. A. Khalil and N. M. Ahmied, "Optimal Tunning of Lead-Lag and Fuzzy Logic Power System Stabilizers Using Particle Swarm Optimization," Expert Systems with Applications, Vol. 36, No. 2, 2009, pp. 2097-2106. doi:10.1016/j.eswa.2007.12.069

[9] E. R. C. Viveros, G. N. Taranto and D. M. Falcão, "Tuning of Generator Excitation Systems Using Meta-Heuristics," IEEE Power Engineering Society General
Meeting, Montreal, 16 October 2006, p. 6. doi:10.1109/PES.2006.1709524

[10] Z. Lubosuy, "Dual Input Quasi-Optimal PSS for Generating Unit with Static Excitation System," Power Plants and Power Systems Control, Vol. 5, 2006, pp. 267-272. doi:10.3182/20060625-4-CA-2906.00051

[11] T. R. Jyothsna and K. Vaisakh, "Design of a Decentralized Non-linear Controller for Transient Stability Improvement under Symmetrical and Unsymmetrical Fault Condition: A comparative Analysis with SSSC," IEEE Power Systems Conference and Exposition, 15-18 March 2009, Seattle, pp. 1-8.

[12] P. Kunder, "Power System Stability and Control," McGraw, Hill, New York, 2001

[13] P. S. Rao and I. Sen, "Robust Pole Placement Stabilizer Design Using Linear Matrix Inequalities," IEEE Transactions on Power Systems, Vol. 15, No. 1, 2000, pp. 3035-3046.

[14] M. A. Abido, "Pole Placement Technique for PSS and TCSC-Based Stabilizer Design Using Simulated Annealing," International Journal of Electrical Power and Energy Systems, Vol. 22, No. 8, 2000, pp. 543-554. doi:10.1016/S0142-0615(00)00027-2

[15] B. C. Pal, "Robust Pole Placement versus Root-Locus Approach in the Context of Damping Interarea Oscillations in Power Systems," IEE Proceedings on Generation, Transmission and Distribution, Vol. 49, No. 6, 2002, pp. 739-745. doi:10.1049/ip-gtd:20020659

[16] L. Rouco and F. L. Pagola, "An Eigenvalue Sensitivity Approach to Location and Controller Design of Controllable Series Capacitor for Damping Power System Oscillations," IEEE Transactions on Power Systems, Vol. 12, No. 4, 1997, pp. 1660-1666. doi:10.1109/59.627873

[17] M. E. About-Ela, A. A. Sallam, J. D. McCalley and A. A. Fouad, "Damping Controller Design for Power System Oscillations Using Global Signals," IEEE Transactions on Power Systems, Vol. 11, No. 2, pp. 767-773, 1996.

[18] S. Panda and N. P. Padhy, "Optimal Location and Controller Design of STATCOM for Power System Stability Improvement Using PSO," Journal of the Franklin Institute, Vol. 345, No. 2, 2008, pp. 166-181. doi:10.1016/j.jfranklin.2007.08.002

[19] R. L. Haupt and S. E. Haupt, "Practical Genetic Algorithms," Wiley, New York, 2004

[20] G. Wang, M. Zhan, X. Xu and C. Jiang, "Optimization of Controller Parameters Based on the Improved Genetic Algorithms," Proceedings of the 6th World Congress on Intelligence Control and Automation, 21-23 June 2006, Dalian, pp. 3695-3698. doi:10.1109/WCICA.2006.1713060

[21] Q. Y. Jiang, Y. J. Cao and S. J. Cheng, "A Genetic Approach to Design a HVDC Supplementary Subsynchronous Damping Controller," IEEE Transaction on Power Delivery, Vol. 20, No. 2. pp. 528-532, 2005. doi:10.1109/TPWRD.2004.838522

[22] Z. L. Gaing, "A Particle Swarm Optimization Approach for Optimum Design of PID Controller in AVR System," 
IEEE Transactions on Energy Conversion, Vol. 19, No. 2, 2004, pp. 384-91. doi:10.1109/TEC.2003.821821

[23] S. Panda, S. C. Swain, P. K. Rautray, R. K. Malik and G. Panda, "Design and Analysis of SSSC-Based Supplementary Damping Controller," Simulation Modelling Practice and Theory, Vol. 18, No. 9, 2010, pp. 1199-1213. doi:10.1016/j.simpat.2010.04.007

[24] M. A. Abido, "Simulated Annealing Based Approach to PSS and FACTS Based Stabilizer Tuning," Electrical Power and Energy Systems, Vol. 22, No. 4, 2000, pp. 247-258. doi:10.1016/S0142-0615(99)00055-1

[25] C. C. A. Rajan, "A Solution to the Economic Dispatch Using EP Based SA Algorithm on Large Scale Power System," International Journal of Power and Energy Systems, Vol. 32, No. 6, 2010, pp. 583-591.

[26] J. Yuryevich and K. P. Wong, "Evolutionary Programming Based Optimal Power Flow Algorithm," IEEE Transactions on Power System, Vol. 14, No. 4, 1999, pp. 1245-1250. doi: $10.1109 / 59.801880$

[27] Q. H. Wu and J. T. Ma, "Power System Optimal Reactive Power Dispatch Using Evolutionary Programming," IEEE Transactions on Power System, Vol. 10, No. 3, 1995, pp. 1243-1249. doi:10.1109/59.466531

[28] S. Panda, "Differential Evolutionary Algorithm for TCSC-Based Controller Design," Simulation, Model, Practice and Theory, Vol. 17, No. 10, 2009, pp. 1618-1634. doi:10.1016/j.simpat.2009.07.002

[29] S. K. Wang, J. P. Chiou, C. W. Liu, "Parameters Tuning of Power System Stabilizers Using Improved Ant Direction Hybrid Differential Evolution," International Journal of Electrical Power and Energy Systems, Vol. 31, No. 1, 2009, pp. 34-42. doi:10.1016/j.ijepes.2008.10.003

[30] J. Kennedy and R. C. Eberhart, "Particle Swarm Optimization," Proceedings of IEEE International Conference of Neural Networks, Vol. 4, 1995, pp. 1942-1948.

\section{Appendix}

Single-machine infinite-bus power system

Generator:

$\mathrm{S}_{\mathrm{B}}=2100 \mathrm{MVA}, \mathrm{H}=3.7 \mathrm{~s}, \mathrm{~V}_{\mathrm{B}}=13.8 \mathrm{kV}, \mathrm{f}=60 \mathrm{~Hz}$,

$\mathrm{R}_{\mathrm{S}}=2.8544 \mathrm{e}-3, \mathrm{X}_{\mathrm{d}}=1.305$ p.u., $X_{d}^{\prime}=0.296$ p.u.,

$X_{d}^{\prime \prime}=0.252$ p.u., $X_{q}=0.474$ p.u., $X_{q}^{\prime}=0.243$ p.u.,

$X_{q}^{\prime \prime}=0.18$ p.u., $T_{d}=1.01 \mathrm{~s}, T_{d}^{\prime}=0.053 \mathrm{~s}, T_{q o}^{\prime \prime}=0.1 \mathrm{~s}$.

Load at Bus-2: $250 \mathrm{MW}$.

Transformer: $2100 \mathrm{MVA}, 13.8 / 500 \mathrm{kV}, 60 \mathrm{~Hz}, \mathrm{R}_{1}=\mathrm{R}_{2}$

$=0.002$ p.u., $\mathrm{L}_{1}=0, \mathrm{~L}_{2}=0.12$ p.u., $\mathrm{D}_{1} / \mathrm{Y}_{\mathrm{g}}$ connection, $\mathrm{R}_{\mathrm{m}}$

$=500$ p.u., $\mathrm{L}_{\mathrm{m}}=500$ p.u.

\section{doi:10.1109/ICNN.1995.488968}

[31] H. Shayeghi, A. Safari and H. A. Shayanfar, "PSS and TCSC Damping Controller Coordinated Design Using PSO in Multi-Machine Power System," Energy Conversion and Management, Vol. 51, No. 12, 2010, pp. 2930-2937. doi:10.1016/j.enconman.2010.06.034

[32] Luonan Chen, Hideya Tanaka, Kazuo Katou, Yoshiyuki Nakamura., "Stability analysis for digital controls of power systems," Electric Power Systems Research, Vol. 55, No. 2, pp. 79-86, 2000. doi:10.1016/S0378-7796(99)00097-8

[33] R. C. Eberhart, J. Kennedy and Y. Shi, "Swarm Intelligence," Morgan Kaufman Publishers, San Francisco, 2001.

[34] C. T. Chen, "Analog and Digital Control Design: Transfer Function, Space State, and Algebraic Methods," Oxford University Press, Cambridge, 1993.

[35] G. I. Rashed, H. I. Shaheen, X. Z. Duan and S. J. Cheng, "Evolutionary Optimization Techniques for Optimal Location and Parameter Setting of TCSC under Single Line Contingency," Applied Mathematics and Computation, Vol. 205, pp. 133-147, 2008.

[36] Y. J. Liu and X. X. He, "Modeling Identification of Power Plant Thermal Process Based on PSO Algorithm," 2005 American Control Conference, 8-10 June 2005, Portland, pp. 4484-4489.

[37] J. Kennedy and R. Eberhart, "Swarm Intelligence," 1st Edition, Academic press, San Diego, 2001.

[38] Panda, N. P. Padhy, "Comparison of particle swarm optimization and genetic algorithm for FACTSbased controller design," Applied Soft Computing, Vol. 8, No. 4, 2008, pp. 1418-1427.

doi:10.1016/j.asoc.2007.10.009

Transmission line: $3-\mathrm{Ph}, 60 \mathrm{~Hz}$, Length $=300 \mathrm{~km}$ each, $\mathrm{R}_{1}=0.02546 \Omega / \mathrm{km}, \mathrm{R}_{0}=0.3864 \Omega / \mathrm{km}, \mathrm{L}_{1}=0.9337 \mathrm{e}-$ $3 \mathrm{H} / \mathrm{km}, \mathrm{L}_{0}=4.1264 \mathrm{e}-3 \mathrm{H} / \mathrm{km}, \mathrm{C}_{1}=12.74 \mathrm{e}-9 \mathrm{~F} / \mathrm{km}$, $\mathrm{C}_{0}=7.751 \mathrm{e}-9 \mathrm{~F} / \mathrm{km}$.

Hydraulic turbine and governor: $\mathrm{K}_{\mathrm{a}}=3.33, \mathrm{~T}_{\mathrm{a}}=0.07$, $\mathrm{G}_{\min }=0.01, \mathrm{G}_{\max }=0.97518, \mathrm{~V}_{\mathrm{gmin}}=-0.1$ p.u. $/ \mathrm{s}, \mathrm{V}_{\mathrm{gmax}}=0.1$ p.u./s,

$\mathrm{R}_{\mathrm{p}}=0.05, \mathrm{~K}_{\mathrm{p}}=1.163, \mathrm{~K}_{\mathrm{i}}=0.105, \mathrm{~K}_{\mathrm{d}}=0, \mathrm{Td}=0.01 \mathrm{~s}$, $\beta=0, \mathrm{~T}_{\mathrm{w}}=2.67 \mathrm{~s}$.

PSSs: sensor time constant $=0.015 \mathrm{~s}, \mathrm{~V}_{\mathrm{S}}{ }^{\max }=0.15$ p.u., $\mathrm{V}_{\mathrm{S}}{ }^{\min }=-0.15$ p.u. 